\title{
Polyandry and paternity affect disease resistance in eusocial wasps: support for the parasite-pathogen hypothesis
}

\author{
Tatsuya Saga ${ }^{1,2,3, *}$, Masaki Okuno ${ }^{2 \#}$, Kevin J. Loope ${ }^{4}$, Koji Tsuchida $^{2}$, Kako Ohbayashi ${ }^{3}$, \\ Masakazu Shimada ${ }^{3}$, Yasukazu Okada ${ }^{5}$
}

\author{
Affiliations: \\ ${ }^{1}$ Tajimi High School, 9-141 Tajimi, Gifu, Japan, 507-0804 \\ ${ }^{2}$ Faculty of Applied Biological Sciences, Gifu University, 1-1 Yanagido, Gifu, Japan, \\ 501-1193 \\ ${ }^{3}$ Graduate School of Arts and Sciences, Department of General Systems Studies, The \\ University of Tokyo, Meguro-ku, Tokyo, Japan, 153-8902 \\ ${ }^{4}$ Department of Biology, Georgia Southern University, Statesboro, GA, USA, 30461 \\ ${ }^{5}$ Department of Biological Sciences, Tokyo Metropolitan University, 1-1 Minami Osawa, \\ Hachioji, Tokyo, Japan, 192-0364 \\ \# Current affiliation: National Agriculture and Food Research Organization Institute of \\ Agrobiological Sciences, 1-2, Owashi, Tsukuba-city, Ibaraki, Japan, 305-8634
}

Short running title: Polyandry and paternity affect disease resistance in eusocial wasps *Address and correspondence: 9-141 Tajimi, Gifu Japan, 507-0804

E-mail: tatsuya.saga@gmail.com 


\begin{abstract}
Polyandry (multiple mating by females) is a central challenge for understanding the evolution of eusociality. Several hypotheses have been proposed to explain its observed benefits in eusocial Hymenoptera, and one, the parasite-pathogen hypothesis, proposes that high genotypic variance among workers for disease resistance prevents catastrophic colony collapse. We tested the parasite-pathogen hypothesis in the polyandrous wasp Vespula shidai. We infected isolated workers with the entomopathogenic fungus Beauveria bassiana and quantified their survival in the laboratory. Additionally, we conducted paternity analysis of the workers using nine microsatellite loci to investigate the relationship between survival and matriline/patriline of the workers. As predicted by the parasite-pathogen hypothesis, nestmate workers of different patrilines showed differential resistance to $B$. bassiana. We also demonstrated variations in virulence among strains of $B$. bassiana. Our results are the first to directly support the parasitepathogen hypothesis in eusocial wasps and suggest that similar evolutionary pressures drove the convergent origin and maintenance of polyandry in ants, bees, and wasps.
\end{abstract}

Keywords: polyandry, patrilines, disease resistance, social wasp, Vespula 


\section{Introduction}

Explaining the adaptive significance of polyandry (multiple mating by females) in eusocial insects has been a central challenge in sociobiology for the past three decades (Crozier and Pamilo 1996). However, since polyandry causes dilution of kin relationships among nestmates, the phenomenon seems contradictory to kin selection theory because high intra-colony relatedness would appear necessary for the evolution of eusociality (Crozier and Pamilo 1996; Queller and Strassmann 1998). Despite there being cost factors to female multiple mating (e.g., time and energy costs, Thornhill and Alcock 1983; predation risk, Arnqvist 1989; pathogen or virus transmission risk, Sherman et al. 1988; Amiri et al. 2016), polyandry and polygyny (presence of multiple queens in a nest) have evolved from ancestral monandry independently in eusocial insects, suggesting selective forces favoring genetic diversity among nestmates (Hughes et al. 2008). Largescale phylogenetic studies have demonstrated that increased colony size is associated with greater paternity frequency and reduced paternity skew, both of which increase intra-colony genetic diversity across species of eusocial Hymenoptera (Jaffé et al. 2012; Loope et al. 2014).

Several plausible hypotheses have been proposed to explain the evolution of multiple mating given these costs (e.g., parasite-pathogen hypothesis, facilitating division of labor hypothesis, and gaining sperm hypothesis, reviewed in Crozier and Fjerdingstad 2001). The parasite-pathogen hypothesis (PPH) invokes the benefits of high intra-colony genetic 
diversity to explain the evolution of polyandry in social insects (Sherman et al. 1988; Shykoff and Schmid-Hempel 1991). The PPH assumes that different matrilines or patrilines of workers within the colony have different susceptibility or resistance to a single pathogen genotype, and also that different pathogen genotypes have different virulence to individuals of matrilines or patrilines (Sherman et al. 1988; Kraus and Page 1998; Sherman et al. 1998). The PPH proposes that the increased intra-colony genetic diversity arising from polyandry could prevent catastrophic colony collapse following challenge by parasites and pathogens, particularly if resistance to them among workers is variable depending on genotype (Sherman et al. 1988). The PPH has been supported only in Apidae and Formicidae, in which families polyandry has originated independently (Baer and Schmid-Hempel 2003; Palmer and Oldroyd 2003; Hughes and Boomsma 2004; Seeley and Tarpy 2007).

Here, we conducted two experiments to test the PPH in a eusocial wasp in Japan. The first aimed to evaluate fungal virulence differences between colonies, and the second aimed to evaluate fungal virulence differences among patrilines, worker emergence date, and their interaction in a more detailed fashion. We challenged multiple patrilines and matrilines of Vespula shidai with multiple strains of the entomopathogenic filamentous fungus Beauveria bassiana. B. bassiana infects a broad range of insect hosts, and one of its identifying features is the formation of its characteristic conidiospore balls (Hajek and Leger 1994; Schmid-Hempel 1998; Schmidt et al. 2011). 
The nesting biology of V. shidai is similar to that of other Vespula (Matsuura 1995; Saga et al. 2017). A new colony is initiated by a single foundress queen that emerges from hibernation in spring. After hibernation, the queen founds the colony and produces workers and the colony grows through the summer, switching to the production of reproductives (males and new queens) from the beginning of fall to the beginning of winter. Mating occurs in the fall, and after the beginning of winter (early December in central Japan), only gynes hibernate, and all workers and males die (Matsuura \& Yamane 1990).

In addition, we investigated whether differences in the growth environment affected resistance to disease, and whether workers that emerged on the same day showed any bias toward specific patrilines. Assuming that the benefits of high intra-colony genetic diversity are the evolutionary cause of polyandry, simultaneous emergence of workers from various patrilines would increase the genetic diversity within the nest. In many organisms, the effects of epigenetics and phenotypic plasticity mean that even individuals of the same genotype exhibit variability in disease resistance due to differences in environmental factors (Pigliucci 2005). In addition, given the homeostasis common within advanced eusocial societies (Oldroyd and Fewell 2007), it seems likely that workers emerging contemporaneously would have experienced very similar environments as larvae (e.g., kind of food and exposure to diseases). 
The PPH has not yet been directly tested in Vespula, a genus phylogenetically independent of Apidae and Formicidae. In this study, our aims were to first test the prediction that matrilines/patrilines differ in their resistance to particular strains of pathogen, and then to determine if pathogen strains vary in their virulence to hosts of the same genotype, which would suggest the potential for classic co-evolutionary hostpathogen dynamics (Schmid-Hempel and Ebert 2003). We also hoped to extend the sparse literature available (Barribeau et al. 2014) on variation in pathogen strain virulence to the same eusocial wasp genotype host.

\section{Material and Methods}

\section{Pathogens}

We used five fungal strains $(\mathrm{A}-\mathrm{E})$ of the entomopathogenic filamentous fungus Beauveria bassiana for experiment 1, and then selected the two most lethal strains (A and C) for experiment 2 . The fungal strains were isolated from five mummy queen larvae from different colonies of $V$. shidai collected in Nakatsugawa City, Gifu Prefecture, Japan, November 3, 2013. The strains were stored on Sabouraud agar medium (0.01 $\mathrm{g} / \mathrm{mL}$ yeast extract, $0.01 \mathrm{~g} / \mathrm{mL}$ bacto peptone, $0.02 \mathrm{~g} / \mathrm{mL}$ L-glucose, $0.02 \mathrm{~g} / \mathrm{mL}$ agar, and distilled water) in a refrigerator. The fungus was cultured on Sabouraud medium three times prior to the experiments. Conidiospore suspensions were prepared from sporulating culture plates (cultured at $25^{\circ} \mathrm{C}, 8-14$ days, 24-h light) in a $0.03 \%$ Tween 80 solution. 
The fungal spore suspension $(30 \mathrm{~mL})$ was quantified using a hemocytometer (Sigma, St.

Louis, MO, USA) and diluted to the required dosage for both experiments: low $\left(10^{6}\right.$ spores/mL) and high $\left(10^{8}\right.$ spores $\left./ \mathrm{mL}\right)$.

\section{Wasps and Experiment Set-up}

\section{Experiment 1: Interaction of matriline and pathogen strain}

We collected about 400 workers from each of five colonies, on November 9, 2014 at Akechi Wasp Festival in Toyota City, Aichi prefecture, Japan (regarding wasp festivals, refer to Nonaka 2010). On the day of collection, the workers were confined within wire mesh cages, one cage per colony, and placed into a room at constant temperature $\left(25^{\circ} \mathrm{C}\right.$ with a 15-h light:9-h dark photoperiod). A 30\% honey solution was provided daily for one week from the collection date, and the workers remaining alive were used in experiment 1 . The workers were placed in a freezer at $-20{ }^{\circ} \mathrm{C}$ for $20 \mathrm{~s}$ to anesthetize them just before conidiospore infection. Individual workers were then completely submerged for $1 \mathrm{~s}$ into either into the high dose fungal spore solution $\left(10^{8}\right.$ spores $\left./ \mathrm{mL}, 30 \mathrm{~mL}\right)$ or into sterile water (30 mL; control). Excess fluid on the workers' body surface was absorbed using filter paper. Each worker was then housed singly in a plastic box $(3 \times 8 \times 10 \mathrm{~cm})$ lined with filter paper, and provided with $500 \mu \mathrm{L}$ water daily. Their survival was checked daily for 7 days, and their recorded survival time (in days) was recorded. If a worker died, 
we moisturized the filter paper in the box with water to maintain humidity at $90 \%$ for two more weeks. We attributed death to B. bassiana where whitish hyphae, a typical feature of the fungus, were seen growing from the corpse.

\section{Experiment 2: Comparison of strain virulence between different worker patrilines}

\section{and emergence dates}

We collected three colonies in Nakatsugawa City, Gifu prefecture, Japan in middle of July 2015 using traditional methods for wasp hunting and keeping (Saga 2019), and labeled them TK, TG, and KM. We placed each colony in a wooden box $(30 \times 30 \times 60$ $\mathrm{cm}$ ) and provided the colonies with meat (purchased chicken heart) and a $30 \%$ honey solution, permitting free outdoor foraging within the original collection areas until October 11, 2015. On this day, we collected combs filled with larvae and pupae from each colony, put the combs in a plastic box with a mesh roof, and set the boxes in a room at constant temperature $\left(25^{\circ} \mathrm{C}\right.$ with a 15 -h light:9-h dark photoperiod). Every $12 \mathrm{~h}$, we transferred newly emerged workers to individual plastic boxes $(3 \times 8 \times 10 \mathrm{~cm})$ lined with filter paper. We conducted experiment 2 using the workers 12-24 h post emergence, administering the low concentration of fungal spore suspension $\left(10^{6}\right.$ spores $\left./ \mathrm{mL} ; 30 \mathrm{~mL}\right)$ of either strain A or strain $\mathrm{C}$, using the same infection protocol as in experiment 1 , including controls. Strains A and C were used because their apparent virulence differed most (Table 1). After inoculation, we placed the workers into individual boxes and fed 
them with $30 \%$ honey solution ( $2 \mathrm{~mL}$ ) every $48 \mathrm{~h}$, checking for death every $12 \mathrm{~h}$ for 15 days. Following death, we collected the worker's antennae and middle legs for genotyping. As in the preliminary experiment, high humidity was maintained in the box to confirm that cause of death was B. bassiana.

\section{Genetic analysis}

We extracted DNA from the workers killed by B. bassiana. Template DNA was extracted from antenna or leg of the individuals by placing them in $50 \mu \mathrm{L}$ of $5 \%$ Chelex solution (Chelex 100,100-200 mesh, Bio Rad) and 0.5 $\mu \mathrm{L}$ of proteinase K $(20 \mathrm{mg} / \mathrm{mL}$, Takara Bio Inc.), then incubating for $24 \mathrm{~h}$ at $56^{\circ} \mathrm{C}$ and $5 \mathrm{~min}$ at $95^{\circ} \mathrm{C}$. We froze $5 \mu \mathrm{L}$ of the supernatant in $45 \mu \mathrm{L}$ of Tris-EDTA buffer (10 mM Tris, $1 \mathrm{mM}$ EDTA, Takara Bio Inc.) before analysis by polymerase chain reaction (PCR). We genotyped workers at nine polymorphic microsatellite loci: List2001, List2003, List2004, List2019, List2020, Rufa5, Rufa19, VMA3 and VMA6 (Thorén et al. 1995; Daly et al. 2002; Hasegawa and Takahashi 2002) using multiplex PCR. We used dye-labeled primers (Applied Biosystems) in combination with a 3-primer labeling method (Schuelke 2000) to perform multiplex PCR with nine primers. Each $10 \mu \mathrm{L}$ PCR reaction included $1 \mathrm{uL}$ extracted DNA, $5 \mu \mathrm{L}$ Qiagen master mix (Qiagen Type-It Microsatellite Kit, Qiagen Inc.), $0.2 \mu \mathrm{L}$ of each reverse primer, $0.2 \mu \mathrm{L}$ (dye-labeled) or $0.1 \mu \mathrm{L}$ (3-primer labeled) of each forward 
primer, $0.15 \mu \mathrm{L}$ FAM-labeled 3-primer tag for each 3-primer-labeled primer pair, and water to total $10 \mu \mathrm{L}$. PCR reaction conditions were $95^{\circ} \mathrm{C}$ for $15 \mathrm{~min}, 35$ cycles at $95^{\circ} \mathrm{C}$ for $30 \mathrm{~s}, 50{ }^{\circ} \mathrm{C}$ for $90 \mathrm{~s}, 72{ }^{\circ} \mathrm{C}$ for $60 \mathrm{~s}$, followed by $60{ }^{\circ} \mathrm{C}$ for $30 \mathrm{~min}$. Fragment analysis was performed on an $\mathrm{ABI}-3730 \times 1$ sequencer using $0.5 \mu \mathrm{L}$ PCR product combined with $15 \mu \mathrm{L}$ HiDi Formamide and 0.15 $\mu \mathrm{L}$ LIZ 500 internal size standard (Applied Biosystems). Allele sizes were called using GeneMarker (SoftGenetics LLC) and checked twice by eye. We used 10 samples to check for linkage, departures from Hardy-Weinberg equilibrium, and null alleles using Genepop 4.4 (Rousset 2008; Supplementary Materials and Table $\mathrm{S} 1)$.

\section{Estimating maternity and paternity}

We used nine microsatellite markers which were suitable for estimating maternity and paternity (see Supplementary Material). To determine patriline membership, we analyzed microsatellite genotypes using the software Colony v2.0.6.5 (Wang 2004). First, genotypes at locus L2001 were set to unknown for individuals from colony TK because genotypes suggested a maternal null allele. We then ran Colony using a maternal sibship constraint for each colony ( $V$. shidai is an obligatory monogynous species). We then reexamined genotypes that were identified as possibly erroneous by Colony, and also rescored genotypes for individuals whose putative fathers' genotypes differed from other fathers at only a single locus, as these are likely the result of genotyping errors. Colony 
was then re-run using the corrected genotypes to produce the final sibship assignments.

Settings for the Colony runs were: updating allele frequencies, inbreeding absent, polygamy for females, monogamy for males, no scaling of full sibship, no sibship size prior, unknown allele frequencies, a long full likelihood run, and 0.01 dropout and other error rates for all loci.

Sibship assignments using Colony identified 3-4 major patrilines per colony. One worker in colony TK and two in colony KM were not assigned to one of the common patrilines, and likely represented minor patrilines, foreign workers, or genotyping errors. These individuals were removed from further analyses.

\section{Statistical analysis}

For experiment 1, we compared each of the Kaplan-Meier survival curves between the infection and control treatment by log-rank test. We also tested the influence of each colony and each strain, and interaction between both on lifespan checked every $24 \mathrm{~h}$ by Cox regression survival analysis with variable selection by stepwise method (stepAIC function, MASS package, R). For Cox regression survival analysis we used colony and strain, which had the lowest survival rate in experiment 1 , as a reference for each comparison. All statistical analyses were conducted in R 3.2.4 (R 2018). 
For experiment 2, we analyzed the relationship between worker emergence date and patrilines using ANOVA. We compared each of the Kaplan-Meier survival curves in a pair-wise fashion between the infection and control treatment by log-rank test. We also tested the influence of each patriline, each strain, each emergence date and their interactions on lifespan by Cox regression survival analysis with variable selection by stepwise method in each colony, since patrilines are nested within colonies (stepAIC function, MASS package, R). For Cox regression survival analysis we used the patriline that had the lowest survival rate in experiment 2 as a reference for comparison within each colony. All statistical analyses were conducted in R 3.2.4 (R 2018).

\section{Results}

The survival time of controls was significantly longer than of the workers infected with each strain of B. bassiana (Table S2). The Akaike information criterion (AIC) value calculated for the full model of the results of experiment 1 (dependent variables: survival time and rate; predictor variable: each colony and each strain, the interaction of the both) was 1368.1. The AIC value calculated in the final model (dependent variables: survival time and rate; predictor variable: each colony and each strain) after performing stepwise model selection was 1351.3. Any interactions were excluded as a variable by the stepwise model selection. We found that differences of colonies and strains had a significant 
bioRxiv preprint doi: https://doi.org/10.1101/869537; this version posted December 14,2019 . The copyright holder for this preprint (which was not certified by peer review) is the author/funder, who has granted bioRxiv a license to display the preprint in perpetuity. It is made available under aCC-BY-NC-ND 4.0 International license.

influence on lifespan in experiment 1 (Table 1). The results of experiment 1 are

illustrated in Fig. 1. 
Table 1. Cox survival analysis investigating the relationship between the lifespan and the strain used for infection, the colony, and the interaction of the both.

\begin{tabular}{l|l|l|l|l|l|l|l}
\hline Dependent variable & Predictor & Coef & Hazard ratio & SE & Z & P & \\
\hline & Strain A vs B & -0.163 & 0.85 & 0.215 & -0.759 & 0.448 & \\
\cline { 2 - 8 } & Strain A vs C & -0.885 & 0.413 & 0.225 & -0.393 & $<0.001$ & $* *$ \\
\cline { 2 - 8 } & Strain A vs D & -0.374 & 0.688 & 0.208 & -1.800 & 0.072 & \\
\cline { 2 - 8 } & Strain A vs E & -0.608 & 0.544 & 0.214 & -2.846 & 0.004 & $* *$ \\
\cline { 2 - 8 } & Colony 3 vs 1 & -1.541 & 0.214 & 0.209 & -7.381 & $<0.001$ & $* *$ \\
\cline { 2 - 8 } & Colony 3 vs 2 & -0.715 & 0.489 & 0.206 & -3.469 & $<0.001$ & $* *$ \\
\cline { 2 - 8 } & Colony 3 vs 4 & -0.702 & 0.495 & 0.200 & -3.519 & $<0.001$ & $* *$ \\
\cline { 2 - 7 } & Colony 3 vs 5 & -0.840 & 0.432 & 0.238 & -3.526 & $<0.001$ & $* *$ \\
\hline
\end{tabular}

significance level, $* * ; P=0.01$ 

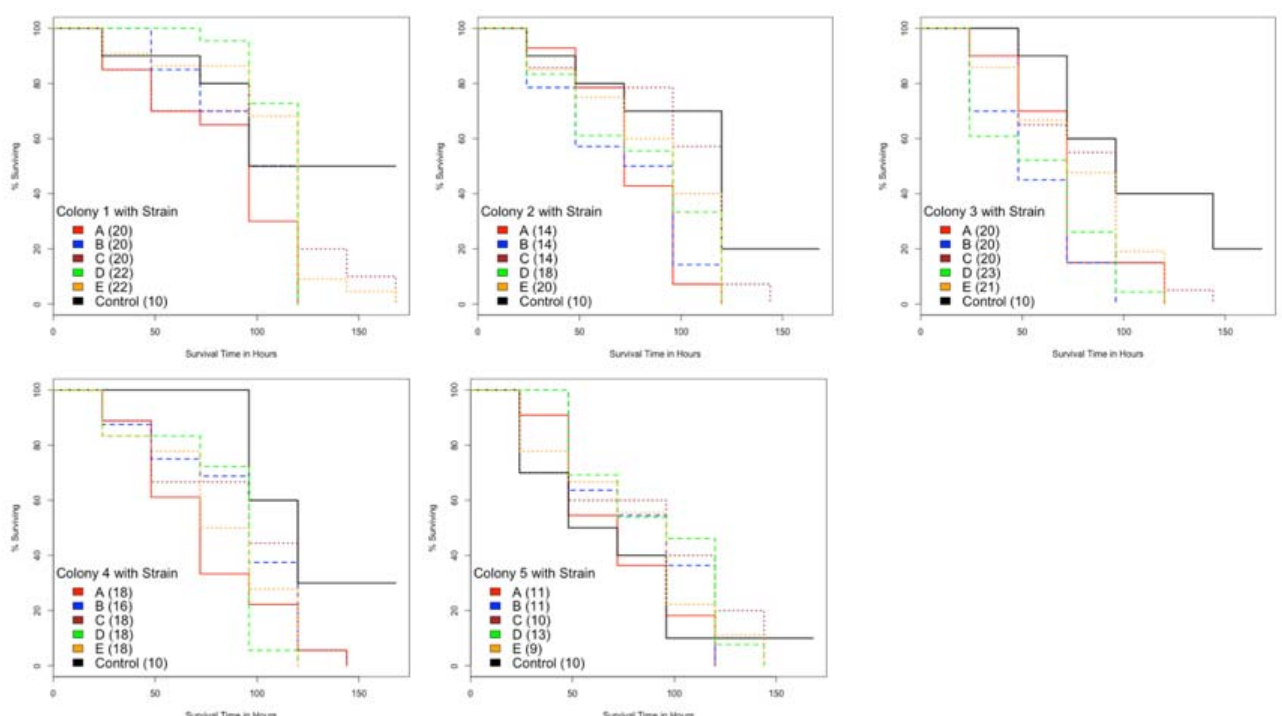

Figure 1. Survival curves for controls and infected workers in each colony. Legends show strains of B. bassiana. Values in parentheses are number of samples. Table 1 shows the statistical analysis of these results.

We did not detect any deviation from Hardy-Weinberg equilibrium, departure from linkage disequilibrium, or null alleles in this population (Table S1), indicating that our chosen nine microsatellite markers were appropriate for matriline and patriline detection. The effective paternity number $\left(k_{\mathrm{e} 3}\right)$ was $3.23 \pm 0.32 \mathrm{SE}$ using the equation of Nielsen et al. (2003).

There was no significant relationship between worker emergence date and patriline in any of the three colonies in experiment 2 (ANOVA: TK, $\mathrm{n}=197, F=0.690, P=$ $0.407 ; \mathrm{TG}, \mathrm{n}=155, F=0.005, P=0.945 ; \mathrm{KM}, \mathrm{n}=215, F=3.023, P=0.083)$. The survival time of the control was significantly longer than that of the workers infected with the two chosen fungal strains in all three colonies (log-rank test, $P<0.001)$. AIC values calculated in the full model using the results of experiment 2 (dependent variables: 
survival time and survival rate; predictor variable: each patriline, each strain, each emerged date and their interaction) in TK, TG, and KM colonies were 956.4, 756.1, and 1044.8. The result after performing stepwise model selection by AIC are presented in Table 2. We detected significant effects of patriline differences, emergence date, and the interaction of both on lifespan of $V$. shidai workers in the TK colony (Table 2). Similarly, we detected significant effects of patriline differences and strain differences on lifespan in the TG colony (Table 2). We detected significant effects of patriline differences and emergence date on lifespan in the KM colony (Table 2). The results of experiment 2 are illustrated in Fig. 2. 
bioRxiv preprint doi: https://doi.org/10.1101/869537; this version posted December 14,2019 . The copyright holder for this preprint (which was not certified by peer review) is the author/funder, who has granted bioRxiv a license to display the preprint in perpetuity. It is made available

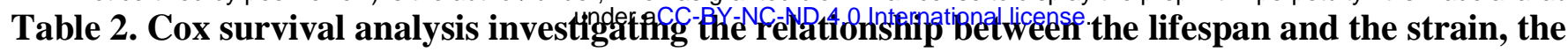

patrilines, the emergence date, and those interactions.

\begin{tabular}{|c|c|c|c|c|c|c|c|c|}
\hline $\begin{array}{l}\text { Dependent } \\
\text { variable }\end{array}$ & Matriline & Predictor & Coef & $\begin{array}{l}\text { Hazard } \\
\text { ratio }\end{array}$ & SE & $\mathrm{Z}$ & $\mathrm{P}$ & \\
\hline \multirow{16}{*}{ Lifespan } & \multirow{9}{*}{$\begin{array}{l}\text { TK, } \mathrm{n}= \\
197, \\
\mathrm{AIC}= \\
956.4\end{array}$} & F3 vs F1 & -1.062 & 0.346 & 0.498 & -2.133 & 0.033 & $*$ \\
\hline & & F3 vs F2 & 0.212 & 1.236 & 0.559 & 0.379 & 0.704 & \\
\hline & & F3 vs F4 & -2.402 & 0.09 & 0.99 & -2.427 & 0.015 & $*$ \\
\hline & & strain & 1.171 & 3.227 & 0.662 & 1.771 & 0.077 & \\
\hline & & emergence date & 0.002 & 1.002 & 0.009 & 0.03 & 0.486 & \\
\hline & & $\begin{array}{l}\mathrm{F} 3 \times \text { emegence } \\
\text { date vs } \mathrm{F} 1 \times \\
\text { emergence date }\end{array}$ & 0.105 & 1.111 & 0.081 & 1.295 & 0.195 & \\
\hline & & $\begin{array}{l}\text { F3 } \times \text { emegence } \\
\text { date vs F2 } \times \\
\text { emergence date }\end{array}$ & -0.091 & 0.913 & 0.090 & -1.009 & 0.313 & \\
\hline & & $\begin{array}{l}\mathrm{F} 3 \times \text { emegence } \\
\text { date vs } \mathrm{F} 4 \times \\
\text { emergence date }\end{array}$ & 0.277 & 1.319 & 0.137 & 2.019 & 0.043 & $*$ \\
\hline & & $\begin{array}{l}\text { strain } \times \text { emergence } \\
\text { date }\end{array}$ & -0.152 & 0.859 & 0.093 & -1.630 & 0.103 & \\
\hline & \multirow{3}{*}{$\begin{array}{l}\text { TG, } \mathrm{n}= \\
155, \\
\mathrm{AIC}= \\
756.1\end{array}$} & F10 vs F9 & 0.274 & 1.315 & 0.221 & 1.237 & 0.216 & \\
\hline & & F10 vs F11 & 0.508 & 1.662 & 0.252 & 2.018 & 0.044 & $*$ \\
\hline & & strain & -0.608 & 0.544 & 0.193 & -3.150 & 0.002 & $* *$ \\
\hline & \multirow{4}{*}{$\begin{array}{l}\mathrm{KM}, \mathrm{n}= \\
215, \\
\mathrm{AIC}= \\
1044.8\end{array}$} & F6 vs F12 & 0.629 & 1.876 & 0.237 & 2.650 & 0.008 & $* *$ \\
\hline & & F6 vs F13 & 0.153 & 1.166 & 0.207 & 0.740 & 0.359 & \\
\hline & & F6 vs F15 & 0.351 & 1.420 & 0.275 & 1.274 & 0.202 & \\
\hline & & emergence date & -0.084 & 0.919 & 0.030 & -2.828 & 0.005 & $* *$ \\
\hline
\end{tabular}


bioRxiv preprint doi: https://doi.org/10.1101/869537; this version posted December 14, 2019. The copyright holder for this preprint (which was not certified by peer review) is the author/funder, who has granted bioRxiv a license to display the preprint in perpetuity. It is made available under aCC-BY-NC-ND 4.0 International license.

significance level $* ; P=0.05, * * ; P=0.01$ 

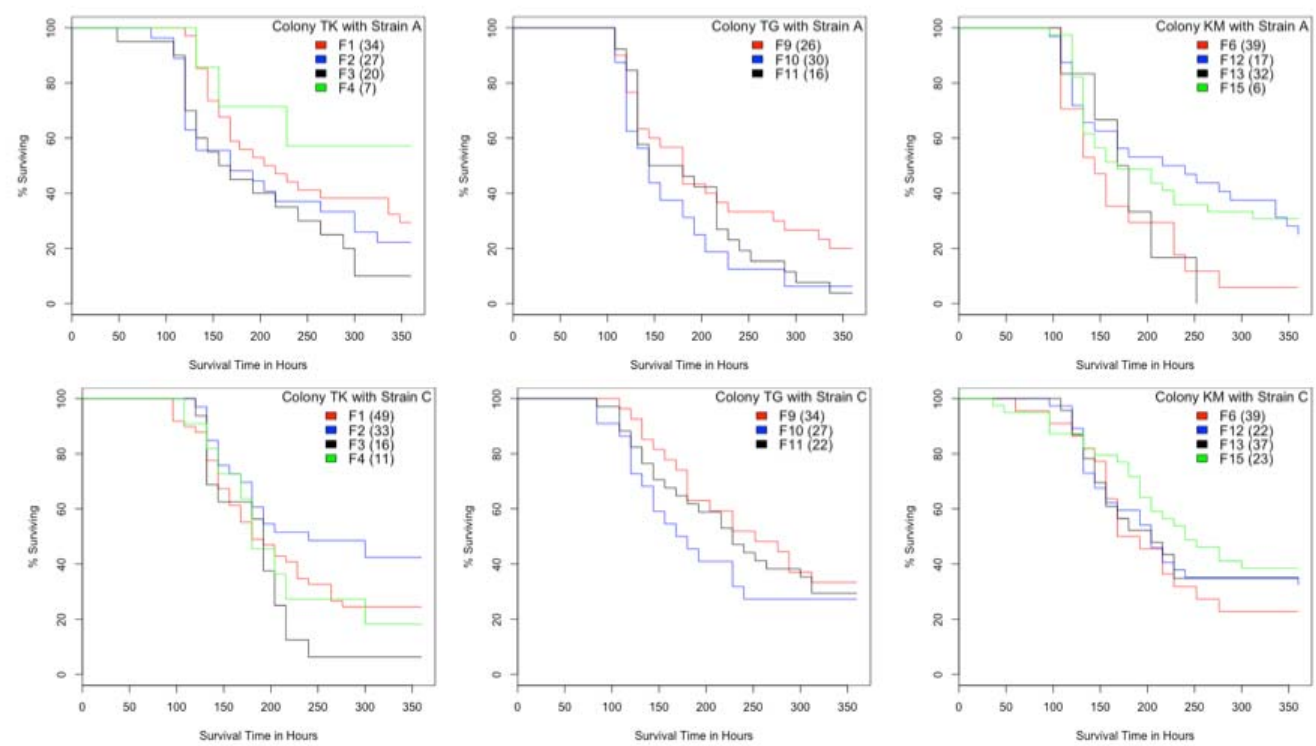

Figure 2. The survival curves of each patriline of each colony on the strain $\mathrm{A}$ and $\mathrm{C}$ in experiment 2. Legends show patrilines. Parentheses are number of samples. We showed results of statically analysis in Table 2 .

\section{Discussion}

The five strains of B. bassiana used in this study all showed virulence to $V$. shidai, and for two of these the survival time of infected workers was significantly shorter than the control (Table S2). We also confirmed that $V$. shidai is polyandrous, with 3-4 major patrilines per colony, similar to other Vespula species (Goodisman et al. 2007; Bonckaert et al. 2008; Loope et al. 2014). Lifespan varied significantly both between colonies (= matrilines) and strains of B. bassiana (Table 1 and 2). Since V. shidai is an obligatory monogynous species, the observed differences in virulence between colonies suggests that matriline differences and/or the interaction of matriline and strain likely play a crucial role in colony resistance to parasites such as B. bassiana. 
We also demonstrated that the lifespan of the workers infected with the fungus varied among patrilines, showing for the first time in eusocial wasps that resistance to pathogens varies depending on patriline. Such patriline differences have been shown in some bees and ants (Palmer and Oldroyd 2003; Baer and Schmid-Hempel 2003; Hughes and Boomsma 2004), as predicted by PPH; worker matrilines and/or patrilines probably have different levels of resistance to a single pathogen genotype. Pathogen variants show differences in virulence to individual matrilines or patrilines. Such variation in resistance among matrilines and patrilines would prevent colony failure as a whole due to reduced disease transmission among nestmates under genotype-genotype interaction in the hostparasite relationship (Sherman et al. 1988). There have been few reports that host survivorship depends on pathogen genotype (but see Barribeau et al. 2014). It is considered that the different strains of $B$. bassiana used in this study possessed different genotypes since they were isolated from different sources, and we demonstrated that the different strains varied in virulence, at least for some patrilines and matrilines. On this basis our results clearly support the PPH.

Dobelmann et al. (2017) compared natural viral infection rates and immune responses among patrilines within colonies of the polyandrous $V$. vulgaris but they found no differences due to patriline, perhaps due to lower sample sizes than those employed here. Our results suggest that the PPH likely explains why high colony genetic diversity is associated with high reproductive success in eusocial wasps, as found by Goodisman et 
al. (2007) and Dobelmann et al. (2017). As observed in other Vespula species (Ross 1986; Goodisman et al. 2007) we found that sperm mixing must have occurred in queens' spermatheca because patrilines were evenly distributed across emergence dates resulting in increased genetic diversity within colonies.

In experiment 2, the environment in which the adult wasps were reared after emergence was under our control, but we did not control the environment of larval and pupal workers before emergence. In the KM colony, survival time of infected workers was dependent on emergence day, suggesting that resistance to pathogens is also affected by the environmental factors pertaining during the larval stage. However, even if some variation in survival is attributable to variation in the larval environment, this is almost certainly independent of the observed association with patriline.

Understanding the evolutionary processes that maintain polyandry in social insects has been one of the central challenges of social insect evolutionary biology in the past three decades (Mattila and Seeley 2007). Here for the first time we have demonstrated that the PPH is one of the evolutionary factors contributing to polyandry in eusocial wasps. Colonies we tested were shown to contain individuals of some patrilines that did not die after infection with $B$. bassiana. Patrilines conferring increased resistance may help a colony to maintain a minimum number of individuals to ensure colony survival and reproduction, and this may be particularly important in the early stages of colony development. $V$. shidai queens are known to usurp young nests of the same or other 
species (Saga et al. 2017). This intra- and interspecific usurpation by $V$. shidai leads to an increase in genetic diversity of nestmates in the early stages, and is likely to contribute to an increase in disease resistance. It is thought likely that increasing resistance to disease was a force that drove the evolution and maintenance of polyandry in eusocial insects. We suggest that our methods should be applied to other species of wasp, since few have been studied. One might expect to find similar results in other obligately polyandrous Vespidae species, although the selective forces that favor facultative polyandry may be quite different (Loope 2015; Loope et al. 2017). Several other hypotheses (e.g., sperm limitation, Kraus et al. 2004; enhanced division of labor, Waibel et al. 2006; conflict reduction, Mattila et al. 2012, Loope 2015) have been proposed to explain the evolution of polyandry, and while they are not mutually exclusive with the $\mathrm{PPH}$, all deserve further research.

\section{Acknowledgments}

The authors would like to thank Katsuyuki Takahashi, Tsutomu Kamata and Kazuo Taguchi for helping me to collect and keep the wasp colonies. We sincerely thanks to Yoshikuni Hodoki for helping DNA analysis. We are very grateful to two anonymous reviewers for their valuable comments on previous versions of the manuscript. This study was supported in part by Takeda Science Foundation, Fujiwara Natural History Foundation, Funding of the Nagano Society for The Promotion of Science, Shimonaka 
Memories Foundation, Takara Harmonist Fund, Environmental research grant from

Nissei Zaidan, and the Dream Project by Come on UP, Ltd.

\section{References}

Amiri E, Meixner MD, Kryger P. 2016. Deformed wing virus can be transmitted during natural mating in honey bees and infect the queens. Sci Rep. 6:33065.

Arnqvist G. 1989. Multiple mating in a water strider: mutual benefits or intersexual conflict? Animal Behav. 38(5):749-756.

Baer B, Schmid-Hempel P. 2003. Bumblebee workers from different sire groups vary in susceptibility to parasite infection. Ecol Lett 6(2):106-110.

Barribeau SM, Sadd BM, du Plessis L, Schmid-Hempel P. 2014. Gene expression differences underlying genotype-by-genotype specificity in a host-parasite system. Proc Nat Acad Sci USA. 111(9):3496-3501.

Bonckaert W, Vuerinckx K, Billen J, Hammond RL, Keller L, Wenseleers T. 2008.

Worker policing in the German wasp Vespula germanica. Behav Ecol. 19(2):272278.

Crozier RH, Pamilo P. 1996. Evolution of social insect colonies: sex allocation and kin selection. Oxford University Press, Oxford. 
Crozier RH, Fjerdingstad EJ. 2001. Polyandry in social Hymenoptera-disunity in diversity? Annales Zoologici Fennici, Finnish Zoological and Botanical Publishing Board. 38:267-285.

Daly D, Archer ME, Watts PC, Speed MP, Hughes MR, Barker FS. 2002. Polymorphic microsatellite loci for eusocial wasps (Hymenoptera: Vespidae). Mol Ecol Notes 2(3):273-275.

Dobelmann J, Loope KJ, Wilson-Rankin E, Quinn O, Baty JW, Gruber MAM, Lester PJ. 2017. Fitness in invasive social wasps: the role of variation in viral load, immune response and paternity in predicting nest size and reproductive output. Oikos. 126(8):1208-1218.

Goodisman MAD, Kovacs JL, Hoffman EA. 2007. The significance of multiple mating in the social wasp Vespula maculifrons. Evolution. 61(9):2260-2267.

Hughes WOH, Boomsma JJ. 2004. Genetic diversity and disease resistance in leafcutting ant societies. Evolution. 58(6):1251-1260.

Hughes WOH, Ratnieks FLW, Oldroyd BP. 2008. Multiple paternity or multiple queens: two routes to greater intracolonial genetic diversity in the eusocial Hymenoptera. $\mathbf{J}$ Evol Biol. 21(4):1090-1095.

Jaffé R, Garcia-Gonzalez F, den Boer SPA, Simmons LW, Baer B. 2012. Patterns of paternity skew among polyandrous social insects: what can they tell us about the potential for sexual selection? Evolution. 66(12):3778-3788. 
Hajek AE, Leger RJS. 1994. Interactions between fungal pathogens and insect hosts. An Rev Entomol. 39:293-322.

Hasegawa E, Takahashi J. 2002. Microsatellite loci for genetic research in the hornets Vespa mandarinia and related species. Mol Ecol Notes. 2(3):306-308.

Kraus B, Page RE. 1998. Parasites, pathogens and polyandry in social insects. Am Naturalist. 151(4):383-391.

Kraus FB, Neumann P, van Praagh J, Moritz RFA. 2004. Sperm limitation and the evolution of extreme polyandry in honeybees (Apis mellifera L.). Behav Ecol Sociobiol. 55(5):494-501.

Loope KJ, Chun C, Michael J. 2014. Colony size is linked to paternity frequency and paternity skew in yellowjacket wasps and hornets. BMC Evol Biol. 14:277.

Loope KJ. 2015. Queen killing is linked to high worker-worker relatedness in a social wasp. Curr Biol. 25(22):2976-2979.

Loope KJ, Lopez-Osorio F, Dvořák L. 2017. Convergent reversion to single mating in a wasp social parasite. Am Naturalist. 189(6):E138-E151.

Matsuura M. 1995. Social wasps of Japan in color. Hokkaido University Press, Sapporo. (In Japanese).

Matsuura M, Yamane S. 1990. Biology of the vespine wasps. Springer, Berlin.

Mattila HR, Seeley TD. 2007. Genetic diversity in honeybee colonies enhances productivity and fitness. Science. 317(5836): 362-364. 
Mattila HR, Reeve HK, Smith ML. 2012. Promiscuous honey bee queens increase colony productivity by suppressing workers. Curr Biol. 22(21):2027-2031.

Nielsen R, Tarpy DR, Reeve HK. 2003. Estimating effective paternity number in social insects and the effective number of alleles in a population. Mol Ecol. 12(11):31573164.

Nonaka K. 2010. Cultural and commercial roles of edible wasps in Japan, in "Edible forest insects human bite back." Food and Agriculture Organization of the United Nations.

Oldroyd BP, Fewell JH. 2007. Genetic diversity promotes homeostasis in insect colonies. Trends Ecol Evol. 22(8):408-413.

Palmer KA, Oldroyd BP. 2003. Evidence for intra- colonial genetic variance in resistance to American foulbrood of honey bees (Apis mellifera): further support for the parasite/pathogen hypothesis for the evolution of polyandry. Naturwissenschaften. 90(6):265-268.

Pigliucci M. 2005. Evolution of phenotypic plasticity: where are we going now? Trends Ecol Evol. 20(9):481-486.

Queller DC, Strassmann JE. 1998. Kin selection and social insects. Bioscience. 48(3):165-175.

R. 2018. The R Project for Statistical Computing. https://www.R-project.olrg/. 
Ross KG. 1986. Kin selection and the problem of sperm utilization in social insects.

Nature. 323:798-800.

Rousset F. 2008. GENEPOP'007: a complete re-implementation of the genepop software for Windows and Linux. Mol Ecol Res 8(1):103-106.

Saga. T. 2019. Evaluation of the productivity of social wasp colonies (Vespinae) and an introduction to the traditional Japanese vespula wasp hunting technique. J Visual Exp. 151:e59044.

Saga T, Kanai M, Shimada M, Okada Y. 2017. Mutual intra- and interspecific social parasitism between parapatric sister species of Vespula wasps. Insectes Sociaux. 64(1):95-101.

Schmid-Hempel P. 1998. Parasites in social insects. Princeton University Press, Princeton, New Jersey.

Schmid-Hempel P, Ebert D. 2003. On the evolutionary ecology of specific immune defence. Trends Ecol Evol. 18(1):27-32.

Schmidt AM, Linksvayer TA, Boomsma JJ, Pedersen JS. 2011. No benefit in diversity? The effect of genetic variation on survival and disease resistance in a polygynous social insect. Ecol Entomol. 36(6):751-759.

Seeley TD, Tarpy DR. 2007. Queen promiscuity lowers disease within honeybee colonies. Proc Royal Soc B. 274:67-72. 
Schuelke M. 2000. An economic method for the fluorescent labeling of PCR fragments.

Nat Biotechnol. 18(2):233-234.

Sherman PW, Seeley TD, Reeve HK. 1988. Parasites, pathogens, and polyandry in social

Hymenoptera. Am Naturalist. 131(4):602-610.

Sherman PW, Seeley TD, Reeve HK. 1998. Parasites, pathogens and polyandry in

honeybees. Am Naturalist. 151(4):392-396.

Shykoff JL, Schmid-Hempel P. 1991. Parasites and the advantage of genetic variability

within social insect colonies. Proc Royal Soc B. 243(1306):55-58.

Thorén PA, Paxton RJ, Estoup A. 1995. Unusually high frequency of (CT)n and (GT)n

microsatellite loci in a yellowjacket wasp, Vespula rufa (L.) (Hymenoptera:

Vespidae). Insect Mol Biol. 4(3):141-148.

Thornhill R, Alcock J. 1983. The evolution of insect mating systems. Cambridge:

Harvard University Press.

Waibel M, Floreano D, Magnenat S, Keller L. 2006. Division of labour and colony

efficiency in social insects: effects of interactions between genetic architecture, colony kin structure and rate of perturbations. Proc Royal Society B.

273(1595):1815-1823.

Wang J. 2004. Sibship reconstruction from genetic data with typing errors. Genetics. 166(4):1963-1979. 
bioRxiv preprint doi: https://doi.org/10.1101/869537; this version posted December 14,2019 . The copyright holder for this preprint (which was not certified by peer review) is the author/funder, who has granted bioRxiv a license to display the preprint in perpetuity. It is made available under aCC-BY-NC-ND 4.0 International license. 


\section{Figure Legends}

Figure 1. Survival curves for controls and infected workers in each colony. Legends show strains of B. bassiana. Values in parentheses are number of samples. Table 1 shows the statistical analysis of these results.

Figure 2. Survival curves for patrilines in each colony with fungal strains A and C in experiment 2. Legends show patrilines. Values in parentheses are number of samples. Table 2 shows the statistical analysis of these results. 